\title{
BIM SUPERIOR APPROACH FOR INFRASTRUCTURE CONSTRUCTION IN THE CZECH REPUBLIC
}

\author{
Josef Zak, Stanislav Vitasek \\ Czech Technical University in Prague, Czech Republic \\ josef.zak@fsv.cvut.cz, stanisla.vitasek@fsv.cvut.cz
}

\begin{abstract}
The article deals with the use of modern technologies for linear construction, the aim of which is to make traditional methods more effective. The need to optimize construction and operational costs is ever more demanding given the rising price of energy leading to a relentless pressure to find saving opportunities. A particular modern technology is presented with the Building Information Modelling (BIM) method, which represents a developing global phenomenon in the building industry. The article summarizes the current legislative process of BIM implementation in the Czech Republic (CR), primarily in the link to public procurement tenders, where the $\mathrm{CR}$ is going to mandate BIM usages in transport projects above $€ 5,700,000$ by 2022. Besides this progress in the legislative situation in the $C R$ has been created an additional overview regarding use of these given methods in different European countries, where they have progressed further in their modern technological application. This integral overview is supplemented with reference to particular transport projects, where BIM has been deployed for different stages of construction production. This takes us from the classical use of a 3D model for earthworks or looking for possible structural collisions, then through 4D for the needs of planning in cost and construction scheduling right up to the 5D, where BIM is linked with cost management. BIM has already been applied in the CR to a limited extent on a few transport projects and there are planned other structures, where BIM should be more intensively brought to bear on the actual workings of the construction process.
\end{abstract}

Keywords: BIM, construction. infrastructure.

\section{Introduction}

As in other European Union states, the Czech Republic (CR) is also looking for new methods of more efficient construction management and infrastructure project administration. Building information modelling (BIM) offers a modern tool for all the stages of the construction project from preparation, construction management and onwards up to actual asset management itself. Additionally, as with all innovative ideas, BIM must go through a process of selling its relevance for a higher rate of successful applicability above any existing traditional solution, and in these terms addressing both the professional community and investors themselves. For example, when digitization and automation took place in the automotive industry, it increased the production efficiency by $75 \%$. A parallel can be drawn in construction. The introduction of Information Modelling in the life cycle of construction has increased both automation and prefabrication in the construction industry. The quantification of savings in transportation construction calculated by individual authors ranges between 8-35 \% [1-4].

The public body covering transportation projects in the Czech Republic is The Czech State Fund for Transportation Infrastructure (SFTI), which decides on matters allocating finances into the individual branches of linear structures. This institution is currently very much interested in BIM use within infrastructure projects. In the CR the implementation of new methods into legislation and more generally introducing awareness of these to professional construction bodies usually takes longer than in other, most usually west European countries, and that is why there is being sought some inspiration abroad, where BIM is already a work in progress $[5 ; 6]$.

\section{Literature review}

The topic of BIM has often been discussed in scientific journals and publications in recent years and not only in regard to transport projects. Professional articles often focus on the application of different possibilities connected with BIM (3D, 4D, 5D) in particular countries or individual branches of construction. This is exemplified in Japan, where a study on BIM use for improving infrastructure project design with contracts for design-bid-build has been extensively elaborated. The authors prove the economic-technical contributions of BIM at different stages of the life cycle with this type of a contract. The important conclusion of this work is the necessity of gaining essential experience before the comprehensive embedding of BIM in the public sector [7]. In the Czech Republic there is also underway an active discussion on BIM involvement in procurement tenders for transport projects, for 
which the SFTI formed a professional team, which is in charge of necessary document preparation for the possible implementation of this method into common practice.

The article focusing especially on the particular implementation of BIM for project management is The effects of BIM and lean construction on design management practice. The idea behind this publication is that of looking for problem areas in project management with the help of the BIM method specifically in Finland, where the research identified the profession of a BIM coordinator as the pivotal factor for successful functioning of BIM. This kind of professional needs experience both with the actual process of physical construction and also theoretical knowledge of the current potentialities of BIM [8]. Both in Finland and other countries, where BIM construction companies are developing actively, there is a problem with the lack of experience with this new method and a very limited circle of readily available specialists $[9,10]$. This brings unacceptable risks for enterprises and thus is a serious limiting factor for active BIM emplacement, and not only with transportation projects. On the basis of this shortage of specialists the biggest technical university in the CR (the Czech Technical University in Prague) decided to start teaching a subject titled The BIM Coordinator.

One of the most important benchmarks of a successfully carried out project is the degree of compliance with the planned budget. These problematic issues of BIM have a special working field designated 5D for this purpose. "The development of 5D (Cost) capabilities is gaining momentum and leading edge project cost management firms are starting to realize the competitive advantages by embracing this 'new-age' approach to cost management." [11]. 5D problems are very large scale and current possibilities of its use are so far only connected with the creation of quantity take-off and cost control during the construction. The quantity take-off on the basis of data gained from the model is very dependent on the level of the actual model detail and even with the detailed processing we are not able to reach the full one hundred per cent of building activities, which will be connected with the building project [12]. Research led by Darren Olsen verified particular BIM contributions for the creation of quantity take-off. There is asserted a time saving that can be up to fivefold, when using BIM, when compared with a classical (manual) method. [13] This presents a huge time saving and also increases the punctuality of given quantity take-offs. Unfortunately, the article also refers to the limiting factors for the creation of quantity take-offs from the model, whereby the principal problem it confirms is the sheer total detail included in the actual model itself. The different levels of particular detail in graphic and non-graphic information thus fundamentally influence the possibility of using the 3D model for other specialists. The regulations for model creators are written out in the BIM document execution plan. In the CR not only private consultancy firms, but also public organizations try to develop the best possible relevant image for this type of work in the transport and construction sector.

In concluding this overview, there is thus urged consideration, whether it is economically advantageous to create an information model for all transport projects. Or indeed, even possibly, where the borderline would be on any decision whether to create a model or not.

\section{Current state of BIM implementation in the Czech Republic}

In addition to the general duty of so-called "good man's care" prescribed by the Act No. 219/2000 Coll. on the assets of the Czech Republic and its involvement in legal relations and the SFTI Act, the effective obligation to use funds was another significant incentive for the SFTI to implement the BIM Resolution No. 958 of the Government of the Czech Republic of 2 November 2016 on the meaning of BIM for construction practice and to propose a further procedure for its implementation. Thus, in furtherance of this, by the Czech Government's resolution No. 958 of 2 November 2016:

- the Ministry of Industry and Trade was appointed as a guarantor for the implementation of the BIM methodology for practice in the Czech Republic;

- the Minister of Industry and Trade, with the support of other members of the Government, to elaborate the Concept of Implementation of the BIM Method in the Czech Republic and submit this to the Government for approval by 31 July 2017 ;

- the Minister of Industry and Trade, in cooperation with other named Ministers, including the Minister of Transport, to create appropriate material and financial conditions for the introduction of the BIM method in the Czech Republic. 
The preparation and implementation of this resolution of the Czech Government further deepened the good cooperation between the Ministry of Industry and Trade and the SFTI. In order to prepare a concept that will be successfully implemented and meet the expectations of the professional community and the entire construction sector, the SFTI representatives were invited to prepare such a concept for the Ministry of Transport.

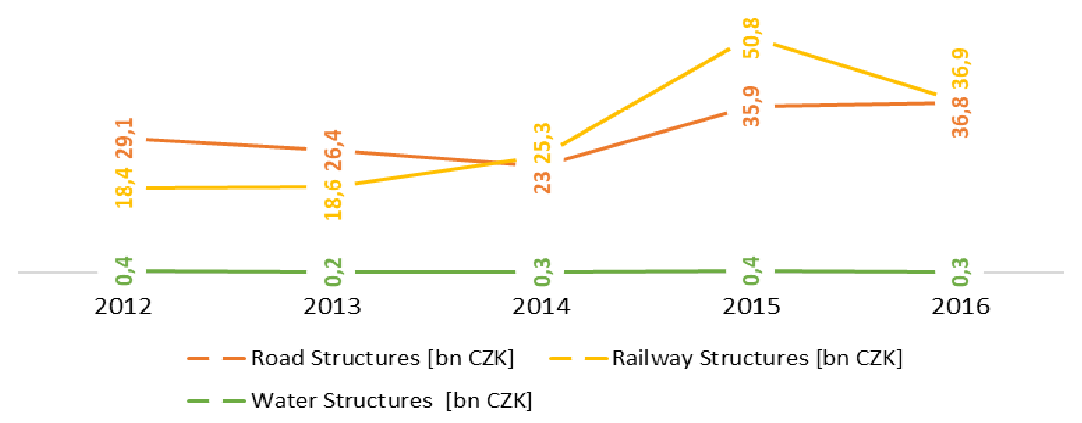

Fig. 1. Financial means provided to SFTI for individual branches of linear structures [14]

Furthermore, the Czech Government Resolution No. 682 of 25 September 2017 approved the Concept of Implementation of the BIM Method in the Czech Republic, contained in Part III of Material 918/17 (hereinafter "the Concept"), prepared in cooperation with the SFTI. The Ministry of Industry and Trade has been entrusted by the Office for Standards, Metrology and Testing (UNMZ) with the intended prospect to use its newly established contributory organization, the Czech Agency for Standardization (CAS), for the implementation of the Government approved measures mentioned in the Concept.

An important aspect of the implementation of this transport sector plan to extend the use of BIM for transport infrastructure for 2018 is successful establishment of a close collaboration between its own expert team established at the SFTI and the UNMZ, in the form of a BIM Concept Division at CAS. The basis for this cooperation will be primarily the coordination of emerging methodologies and standards. In accordance with the above mentioned steps the UNMZ have established ' 152 TNK': the so called Technical Normalization Committee (TNC) for BIM. The committee name can be translated as the Information Organization of Construction and Building Information Modelling.

\section{Public procurement}

When the new Czech Law on public procurement was written, one of the bases for the drafting of this document is the Directive of the European Parliament and of the EP Council 2014/24/EU. This document recommends utilizing principles of Information Modelling in construction life cycle. According to the Law on Public Procurement, § 103, Paragraph 3, the "contracting authority may specify in tender conditions mandatory requirement to use special electronic formats, including the tools of information modelling." This law came into force on 1st October, 2016, streamlining the undecided investors by allowing governmental authorities to require the use of the information model for the construction and preparation of defined works in the Czech Republic [6].

The SFTI issued a press release declaring the intention to gradually introduce the BIM principles into infrastructure projects design and construction at the end of 2016. Such press releases played the key role in informing the market about the SFTI intentions giving the companies, active in infrastructure construction business, the early message that they have to prepare for upcoming changes in procurement. These press releases followed the Government Resolution dated 2nd November, 2016, No. 958. This resolution stated the importance of BIM for civil engineering daily practice and suggested several next steps for BIM introduction in the transport sector. In acknowledgement of the need to tackle the subject matter, the SFTI established an Expert Working Group (EWG) dedicated to the topic of Building Information Modelling and its implementation within the transport sector. This working group has been formed from representatives from the governmental agencies, design companies, general contractors and academia [6].

The SFTI declared that, in cooperation with its supported agencies (the Road and Motorway Directorate of Czech Republic and Railway Infrastructure Administration), they plan the use of BIM 
in several pilot projects in 2017 and 2018. The goal is to broaden the use of digital methods in projects financed by the SFTI. A detailed description of the steps made by the SFTI and other agencies can be found in their publication [4].

The EWG began work on three basic parallel tasks in 2017:

- preparation of the strategy for the introduction of BIM in any construction of transport infrastructure;

- support for the preparation of pilot projects, including their implementation;

- knowledge sharing and training of state representatives.

The Road and Motorway Directorate of the Czech Republic and the Railway Infrastructure Administration began their selected pilot projects in 2017. Now (February 2018) there are five ongoing pilot projects in the Czech Republic that utilize BIM methodologies.

\section{BIM and its practical utilization}

Large infrastructure contractors find quickly significant advantages in the utilization of BIM principles. The use of the data driven processes and technologies is constantly evolving throughout business unit operations and across countries. By the very quality of its virtual manner, the processes that streamline construction and enhance use of advanced technologies can be easily replicated at other construction projects, when the know-how is shared.

Data are utilized to identify inaccuracies and clashes in project documentation minimizing risks by resolving potential construction issues before they happen onsite in later phase. When the information model in prepared according to the needs of construction, then the information on the construction works is rather taken from the information model, when appropriate, than from the 2D project documentation. An extremely important practice for this data use has been identified for earthworks, pavement/track-bed construction and survey works. For such purposes, machines (bulldozers, graders, pavers, excavators) are equipped with GNSS or UTS machine control systems. Data are converted in machine-readable file formats and loaded in control boxes that, in turn, control the machine hydraulic systems.

Operators have a display in view, where they can select automatic positioning or indicative modes. Machines equipped with these technologies are capable of achieving significantly higher production performance and improved precision. There are many other examples of projects that utilize data in this manner. Buitering Parkstad Limburg, Netherlands, Railway modernization Ceska Lipa, D4 Skalka - Crossroads II / 118, D1 Prerov - Lipnik nad Becvou in the Czech Republic, and D1 Budimir-Bidovce in Slovakia are all examples of machine control technologies and data utilization becoming standard. A typical cross section with the view on several parts of the construction project (underpass, underground utilities, platforms, railways station, two bridges) can be seen in the following Figure 2.

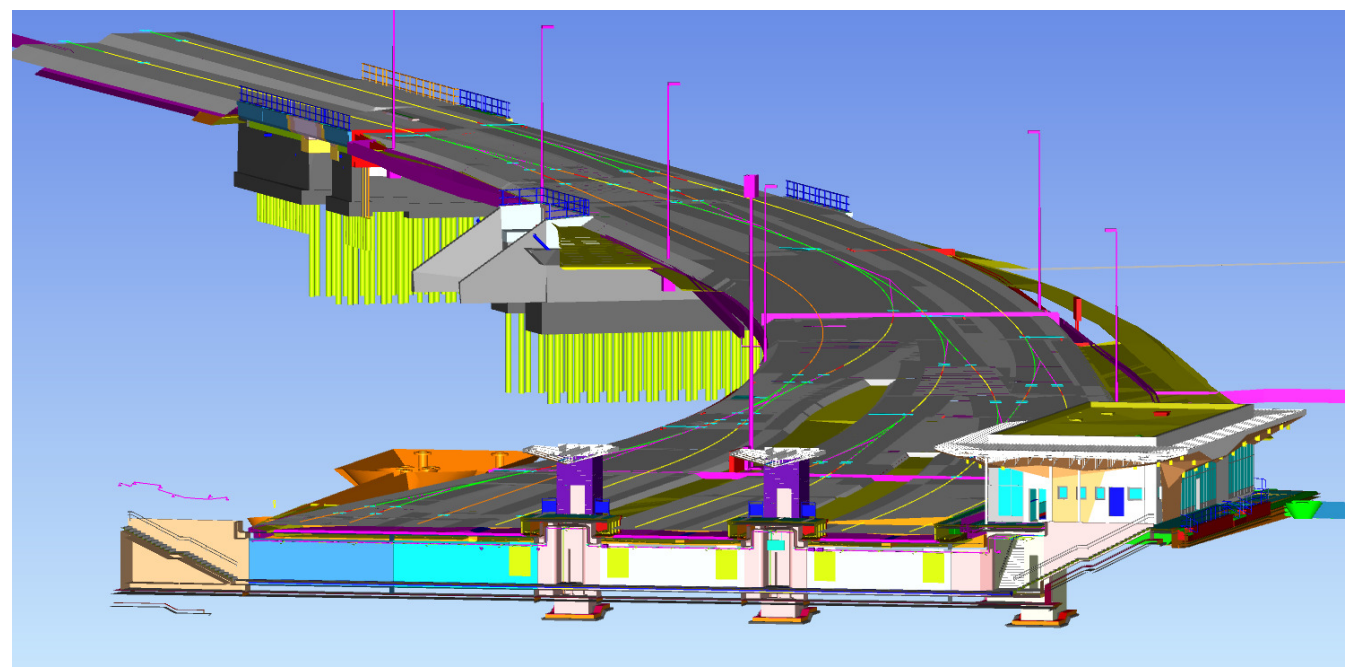

Fig. 2. Railway modernization Ceska Lipa 
In practice, infrastructure asset information and project information are replicated into data (electronic form), by design in the project in the form of one multidimensional coordinated model and accompanying documents that range from quality assurance plans to contract documents. The utilization of these BIM processes is being widely adopted across several projects, by project teams that have learned how to excel using digital environments and as the infrastructure industry recognizes the benefits. Worth mentioning examples of the advanced use of this digital environment during the project delivery phase include: "4D planning", which is the result of adding a time dimension to the $3 \mathrm{D}$ model and "5D modelling" by using the 3D model to produce accurate and transparent bill of quantities. 6D BIM is associated with the use of data to facility management. Than seventh BIM dimension is associated with calculation of the project's embodied carbon. The use of information models and improvement in data processing techniques have further led to wider use of survey techniques such as laser scanning, photogrammetry and the creation and utilization of Digital Terrain Models for earthworks in daily construction work routine.

"4D planning" is typically referred to as 4D simulation and construction planning. Thus, there is a linking of the schedule and time as the 4th dimension to the 3D model. If these principles are applied, then $4 \mathrm{D}$ planning supports construction planning and assesses the impact of proposed design features and construction technologies on both construction schedules and workflow. These simulations provide valuable information concerning on which basis construction schemes are to be reconsidered or changed. Software used for such simulations is capable of detecting schedule-space anomalies and minimizes risk during construction. As an example, reconsideration of reinforcement (steel bar shapes and positions) was undertaken, when the reinforcing work-flow was simulated on the Kungens Kurva project in Stockholm, Sweden, or, when several underground utilities and construction processes were changed in the Ceska Lipa project in the Czech Republic.

5D modelling puts 3D models, schedules and pricing together. As the model grows in complexity, it becomes the basis of project management. 5D modelling may be performed for two stages - as an estimate of future construction costs or to monitor performance of construction teams and machinery. When used as a forecast, such data-rich simulations allow necessary decisions to be made at an early stage of project preparation in order to influence the total project cost.

The performance of each individual worker or machine may be evaluated and linked to penalty/bonus systems on site when 5D modelling is continually applied during construction. The D4 Skalka - Interchange II/118 in the Czech Republic is a project, where cost monitoring was piloted. The project manager utilized these techniques to monitor the ongoing project as well as enhance his forecast for the cost of future projects.

Mobile technologies have also developed in familiar sight on multiple construction sites, with light information and communication technologies (ICT) (smart-phones, tablets, QR codes readers) linked to the databases and Common Data Environment. This access, when and where needed, to a coordinated model, databases, project drawings and other project documentation improves the efficiency, quality of work, reduces rework demands, time spent searching for information and thus also the environmental impact. Such a use of mobile technologies has grown intrinsically from their potential for data and technology access, as construction industries find ever more innovative uses for them.

Such mobile devices are also utilized to produce paperless quality documentation, carry out site inspections and record them in database, mark-up drawings and keep real time site progress records on projects. This thoroughly selected moves towards paperless documentation with the use of ICT that has created efficiencies in administrative processes, as well as created data rich environments that can be used by project management and to drive continuous improvement during the construction process. One example uses data from health and safety inspections (accidents near misses, good practice) and quality checks (punch lists, quality control plans, amendments to handover documents) to analyse trends and address them accordingly during the project execution.

As well as the above mentioned uses, BIM models are applied to traffic safety inspections and visualizations in the Netherlands. Construction and infrastructure projects benefit from the use and application of 3D visualization. Context is an integral aspect, when developing and creating visualizations. Understanding of construction sequence, methods, manpower and materials is required 
to enable effective representations of real-world construction processes. Visualizations are used for traffic safety inspections and to create a link between the client and contractor, as it is far easier to overcome obstacles and delays, when both understand the project, how it is proceeding and over-all, what it looks like. Visualizations are also used, when communicating aspects of a project in public presentations prior to actual project preparations and construction. A typical project using these techniques is "A4all" A4 Delft - Schiedam or "Avenue2," which is a double-layered traffic tunnel under Maastricht, the Netherlands.

The BIM model and project data are also used for many types of analyses necessary for construction permits and environmental impact assessments. Traffic flow analysis that evaluates the probability of congestion and suitable selected solutions as well as flood risk analysis, are both good examples. These analyses were used in Leiden, the Netherlands, when modernization of one of the intercity cross sections was taken through to an interchange. The use of data in ICT technologies and construction automation both enhance the quality and lower the cost of infrastructure design and construction.

\section{Conclusions}

1. The reported activity of the Ministry of Transport asserts the aim to implement BIM in coming years, so that all public projects above $€ 5,700,000$ financed from government resources are going to use the BIM methods by 2022. Based on the Ministry of Industry and Trade study [14] this value has been identified to be economically viable for all projects. The prepared methodologies are going to supporting governmental bodies and contracting authorities to implement the BIM methods at smaller projects, when they foresee the benefit. At the moment there are several pilot projects in BIM, which should bring extensive experience to public clients and the industry itself. On the basis of these experiences, the methodologies for BIM integration will be prepared by expert teams from the Ministry.

2. At the same time it is planned that integration of the principles of information modelling and processes related to digitization of the construction industry will be further developed with the execution of additional pilot projects every year.

3. The paper summarizes examples from projects, in which both authors have worked, on using the BIM technologies over the last two years. At the moment, the use of information models is usually exemplified by collaboration between design offices, contractors and sub-contractors in order to achieve savings during construction, quality improvement, and indeed health and safety.

4. The key role of the whole process is played by the general contractor, who defines the conditions of cooperation, the technical content of the information model and the ways it can be used and who bears the initial cost associated with data preparation. Wide experience from these projects is very valuable in further developing this subject matter in the Czech construction industry.

5. Experience from the implemented projects demonstrates that prudent use of data, ICT technologies and construction automation improves quality and reduces the construction costs of infrastructure projects.

\section{Acknowledgements}

This work was supported by the Grant Agency of the Czech Technical University in Prague, grant No. SGS18/023/OHK1/1T/11.

\section{References}

[1] “NBS National BIM Survey.” 2013. NBS - Royal Institute of British Architects (RIBA).

[2] Köhler N. "Virtuellt Byggande Ska Sänka NCCs Byggkostnader (Virtual Construction Will Reduce NCC's Construction Cost)." Bygginustrin, 2008.

[3] Eastman C. BIM handbook: a guide to building information modeling for owners, managers, designers, engineers and contractors. 2nd ed. Hoboken, NJ: Wiley, 2011. ISBN 978-0-470-541371.

[4] Horelica Z., Mertlova O., Vykydal I., Zak J. "Utilization of digital methods and introduction of information modeling of buildings as a tool for achieving higher efficiency of buildings financed 
by the State Fund of Transport Infrastructure.” Roads and Railway (Silnice a železnice), no. 1., 2017, ISSN 1801-822X.

[5] Matejka P., Ruzicka J., Hajek P., Tomek, A., Kaiser J., Veselka J. "The implementation of building information modeling into educational programs at CTU in prague. "Paper presented at the CESB 2016 - Central Europe Towards Sustainable Building 2016: Innovations for Sustainable Future, 2016, pp. 853-860.

[6] Zak J., Macadam H. "Utilization of building information modeling in infrastructure's design and construction.” IOP Conf. Ser.: Mater. Sci. Eng. 236 012108, BESTInfra 2017, doi:10.1088/1757899X/236/1/012108

[7] Minagawa M., Kusayanagi S. "Study on BIM utilization for design improvement of infrastructure project." Paper presented at the Procedia Engineering, 125, 2015, pp. 431-437. 10.1016/j.proeng.2015.11.113.

[8] Tauriainen M., Marttinen P., Dave B., Koskela L. "The effects of BIM and lean construction on design management practices." Paper presented at the Procedia Engineering, 164, 2016, pp. 567-574. 10.1016/j.proeng.2016.11.659.

[9] Volkov A., Chelyshkov P., Lysenko D. "Information management in the application of BIM in construction. the roles and functions of the participants of the construction process." Paper presented at the Procedia Engineering, 153, 2016, pp. 828-832. 10.1016/j.proeng.2016.08.250.

[10] Matejka P., Tomek A. "Ontology of BIM in a construction project life cycle." Paper presented at the Procedia Engineering, 196, 2017, pp. 1080-1087. 10.1016/j.proeng.2017.08.065.

[11] Smith P. "Project Cost Management with 5D BIM." Paper presented at the Procedia - Social and Behavioral Sciences, 226, 2016, pp. 193-200. 10.1016/j.sbspro.2016.06.179.

[12]Zima K. "Impact of information included in the BIM on preparation of bill of quantities." Paper presented at the Procedia Engineering, 208, 2017, pp. 203-210. 10.1016/j.proeng.2017.11.039.

[13] Olsen D., Taylor, M. "Quantity Take-Off Using Building Information Modeling (BIM), and Its Limiting Factors." Paper presented at the Procedia Engineering, 196, 2017, pp. 1098-1105. 10.1016/j.proeng.2017.08.067.

[14] Ministry of Industry and Trade. "Strategy for BIM implementation in the Czech Republic." Department of Construction and Building Materials, September 2017. 